\title{
Influence of the spatial variability of rainfall on hydrograph modelling at catchment outlet: a case study in the Cevennes region, France
}

\author{
Isabelle Emmanuel ${ }^{1}$, Olivier Payrastre ${ }^{1 a}$, Herve Andrieu ${ }^{1}$ and Felicien Zuber $^{1}$ \\ ${ }^{1}$ LUNAM université, Ifsttar, Département GERS, Laboratoire Eau et Environnement, Bouguenais, France
}

\begin{abstract}
The influence of rainfall spatial variability on hydrographs modelling at catchment outlet remains an open scientific debate. [1] have proposed rainfall variability indexes aiming at summarising the influence of rainfall spatial organisation on hydrographs features. This preliminary work was based on a large simulated database. The present article shows how the proposed indexes may be used in a real case study to discriminate rainfall events for which information on spatial rainfall organization is crucial for hydrograph modelling, and therefore to better illustrate the added value of high resolution rainfall information as input of hydrological models. The presented case study is located in the Cevennes Region in south-eastern France. The tested flow events are split into two subsets according to the values of the rainfall variability indexes. The comparison between modelled and measured hydrographs is then performed separately for each subset. The results obtained suggest that, on average, modelling results taking into account high resolution rainfall data are significantly improved for the subset for which the influence of rainfall variability is expected to be significant according to the indexes values. Although limited to a relatively small number of hydrographs, this case study can be viewed as a first confirmation of the pertinence of the rainfall variability indexes proposed in [1] to investigate the influence of rainfall spatial variability on the shape of hydrographs at catchment outlet.
\end{abstract}

\section{Introduction}

What is the actual influence of rainfall spatial variability on the hydrograph at catchment outlet? Interest for this question has been growing thanks to both the increasing availability of weather radar data and the development of distributed hydrological models. This subject is relevant for both research and practical issues. Concerning research, it contributes to a better understanding of how the spatial variability of rainfall propagates up to the catchment outlet according to catchment features, and therefore to the development of adapted modelling strategies. Concerning the operational side, managers of hydrological systems would take advantage of knowing the conditions for which a spatially detailed knowledge of rainfall and the incorporation of this information in hydrological models may lead to more accurate flood modelling results. Unfortunately, published studies on this topic reach contrasting conclusions [2-6].

The paper contributes to the assessment of the influence of rainfall spatial variability on hydrograph modelling results, at the catchment outlet, by carrying on with the work developed in [1]. In this preliminary work, the authors proposed rainfall variability indexes detecting situations for which rainfall spatial variability may exert a great influence on catchment response at its outlet. These indexes were evaluated thanks to an important simulated database obtained thanks to a simulation chain (a stream network model, a rainfall simulator and a distributed hydrological model). This present paper aims now to

\footnotetext{
a Corresponding author: olivier.payrastre@ifsttar.fr
}

illustrate the pertinence and usefulness of those indexes in a real-world case study conducted in the Cevennes Region in south-eastern France, which is prone to flash flooding. For this purpose, the rainfall variability indexes have been used to stratify the analysis by splitting the sample of tested hydrographs into two subsets: one subset grouping the hydrographs expected to be only weakly affected by rainfall variability, and a second subset grouping the hydrographs expected to be significantly affected by this variability. The results of hydrological modelling obtained for the two subsets are then compared. This separation is expected to ease the analysis of modelling results, by helping to distinguish modelling errors related to the representation of rainfall variability and other sources of errors.

The article is organized as follows. Section 2 includes a presentation of the Cevennes case study. Section 3 provides all the details about the methodology applied. Section 4 describes the obtained results, and Section 5 offers some discussion of these results. Finally, Section 6 presents the conclusions of this work. 


\section{Presentation of the case study}

\subsection{The Cevennes Region and the selected datasets}

The Cevennes Region encompasses a medium elevation mountain range located in the south-eastern part of the Massif Central zone. This range ends in its southeastern stretch with a plateau and plain area extending up to the Mediterranean coast. The region displays typical Mediterranean climate and is subject to heavy rainfall events during the autumn season, causing flash floods that sometimes result in considerable damages and losses. The present case study will focus on three of these catchments: the Gardon $\left(1,858 \mathrm{~km}^{2}\right)$, Ceze $\left(1,355 \mathrm{~km}^{2}\right)$, and Vidourle $\left(798 \mathrm{~km}^{2}\right)$ rivers.

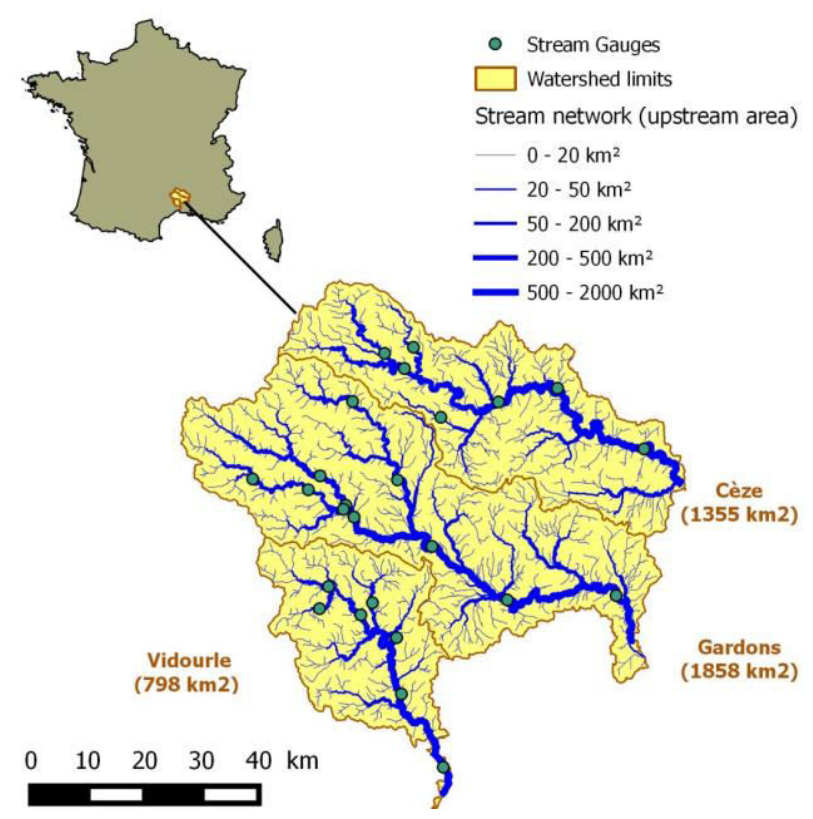

Figure 1. Location of the tested catchments in The Cevennes region (South East of France).

The region is covered by a network of rain gauges, whose density is roughly 1 gauge per every $150 \mathrm{~km}^{2}$, plus two weather radars providing the quantitative precipitation estimates (QPEs) with high spatial $(1 \mathrm{~km} \mathrm{x} 1 \mathrm{~km})$ and temporal $(5 \mathrm{~min})$ resolutions. The available operational datasets have been submitted to a thorough quality control and can be considered of above average accuracy [7].

For purposes of this study, we used hourly rainfall fields of $1 \mathrm{~km}$ x $1 \mathrm{~km}$ spatial resolution obtained by the radar rain gauge merging technique proposed by [8], which show a good level of accuracy if compared to other QPEs products.

The studied catchments also include 16 stream gauges adapted to high flow measurements and thus able to provide flood hydrographs of sufficiently good quality. These gauges are mainly located at the outlet of relatively large basins, with an upstream catchment area ranging from $42 \mathrm{~km}^{2}$ to $1,855 \mathrm{~km}^{2}$ (median value: $244 \mathrm{~km}^{2}$ ).

For purposes of this case study, the flood hydrographs were selected based on their unit peak flow, defined as
$\mathrm{Q}_{\max } / \mathrm{S}^{0.8}$ (with $\mathrm{Q}_{\max }$ the hydrograph peak flow and $\mathrm{S}$ the surface area of the upstream catchment). A threshold of $2.5 \mathrm{~m}^{3} / \mathrm{s} /\left(\mathrm{km}^{2}\right)^{0.8}$ was set to allow selecting just those rain events causing significant hydrological reactions. This point is important since the CINECAR hydrological model used herein was designed to model only this category of intense flood events.

During the 2007-2012 period selected for the study, 25 flood hydrographs related to 7 rainfall events reached a unit peak flow exceeding this threshold at one of the 16 stream gauges. Table 1 lists the number of hydrographs recorded for each event, along with the mean rainfall accumulations for the associated catchments and the mean surface area of these catchments.

\begin{tabular}{|c|c|c|c|}
\hline Event Date & $\begin{array}{c}\text { Number of } \\
\text { hydrographs }\end{array}$ & $\begin{array}{c}\text { Mean rainfall } \\
\text { accumulation } \\
\text { on the } \\
\text { selected } \\
\text { catchments } \\
(\mathrm{mm})\end{array}$ & $\begin{array}{c}\text { Mean area } \\
\text { of the } \\
\text { selected } \\
\text { catchments } \\
\left(\mathrm{km}^{2}\right)\end{array}$ \\
\hline $\begin{array}{c}19 \text { October } \\
2008\end{array}$ & 4 & 166 & 705 \\
\hline $\begin{array}{c}31 \text { October } \\
2008\end{array}$ & 7 & 252 & 646 \\
\hline $\begin{array}{c}29 \text { December } \\
2008\end{array}$ & 3 & 138 & 445 \\
\hline $\begin{array}{c}6 \text { September } \\
2010\end{array}$ & 1 & 178 & 212 \\
\hline $\begin{array}{c}29 \text { October } \\
2010\end{array}$ & 4 & 174 & 532 \\
\hline $\begin{array}{c}21 \text { December } \\
2010\end{array}$ & 1 & 514 & 284 \\
\hline $\begin{array}{c}01 \text { November } \\
2011\end{array}$ & 5 & 160 & 60 \\
\hline
\end{tabular}

Table 1. Characteristics of the selected hydrographs.

\subsection{The Cinecar model}

The CINECAR hydrological model [9] is a distributed model based on a representation of the catchment as a ramified series of stream reaches, to which both left and right-hand hillslopes are connected. For the sake of simplicity, the hillslopes are represented by schematic rectangular shapes, and the river reaches are assumed to have a rectangular cross-section. This model only depicts the rapid runoff and is suited for modelling the rising limb and peak phases of significant flood events. The Soil Conservation Service-Curve Number (SCS-CN) model is used to compute runoff rates and the corresponding effective rainfall on hillslopes at each computation time step. The effective rainfall is then propagated onto both the hillslopes and the downstream river network using either the kinematic wave model or the Hayami solution for the diffusive wave model [10]. The diffusive wave model is used in order to model the attenuation of flood waves downstream river reaches with slopes of less than $0.6 \%$, while the kinematic wave is used for all other river reaches.

This application of the hydrological model was validated with respect to measured data. It provided satisfactory 
results specifically for the Cevennes Region [9], with an average Nash criterion computed for single events equal to 0.49 . In addition, a comparative test between Cinecar and GR4 [11] was conducted for the Anduze stream gauge on the Gardon River, leading to the conclusion that both models had similar performances for the most intense events (i.e. a unit peak discharge exceeding 2.5 $\left.\mathrm{m}^{3} / \mathrm{s} /\left(\mathrm{km}^{2}\right)^{0.8}\right)$.

The same model version has been used herein without any adjustments. The model spatial resolution is determined by the hillslopes dimensions: all 3 catchments considered are divided into 2,282 hillslopes, with a median surface area of $1.5 \mathrm{~km}^{2}$. The model can therefore be considered as well suited to account for high resolution information on rainfall and associated spatial variability often observed in the Cevennes Region.

\section{Method}

\subsection{Principle of separation in two sub-sets}

This section presents the method applied in the case study, to illustrate how rainfall variability indexes may help to identify the influence of rainfall spatial variability on modelling results at catchment outlet. The adopted method [12] relies on splitting the tested set of events into two homogeneous subsets, namely: 1) events for which rainfall spatial variability is expected to exert a significant influence on the observed hydrograph at the catchment outlet; and 2) events for which this variability is expected to exert a weak influence. The underlying assumption is that measurement and modelling errors will be statistically similar for both subsets excepted for errors associated with the representation of rainfall spatial variability. Thus, such segmentation should help to highlight the importance of detailed information on rainfall spatial variability on hydrograph modelling results.

The criterion used to split the set of events must be fully independent of the model. That constraint is satisfied by defining the segmentation criterion from rainfall characteristics.

\subsection{Presentation of the rainfall variability indexes used}

The rainfall spatial variability indexes proposed by [1] were specifically designed to detect situations for which rainfall spatial variability may exert a great influence on catchment response. The analysis conducted based on simulations showed that the proposed indexes, if compared to those of $[13,14]$, offer a similar quantification of the impact of rainfall spatial variability on hydrograph peak time, but explain slightly better the impact on hydrograph amplitude.

These indexes are based on a comparison between the catchment width function and the rainfall width function. The width function, $w(x)$ defined as the portion of the catchment area at a flow distance $x$ from the outlet [15], is representative of the spatial structure of the catchment (and implicitly of catchment response for a spatially homogeneous rainfall). It is constant for a given catchment. The rainfall width function, denoted $\mathrm{w}_{\mathrm{P}}$, is defined as the proportion of rainfall on the catchment falling at a flow distance $x$ from the outlet, and combines information on rainfall spatial organisation and catchment structure. The influence of rainfall spatial organisation on the hydrological response is assessed by comparing the two width functions in their cumulative distribution form. As shown in Figure 2, the first index, denoted VG, is defined as the absolute value of the maximum vertical difference between the two width functions The second index, denoted HG, is then defined as the corresponding difference between both width functions divided by the length of the longest hydrological path of the catchment. VG values close to zero indicate a rainfall distribution over the catchment revealing weak spatial variability. The higher the VG value, the more concentrated the rainfall over a small part of the catchment. HG values close to 0 reflect a rainfall distribution either concentrated close to the catchment centroid position or spatially homogenous. Values less than 0 (greater than 0 ) indicate that rainfall is distributed downstream (or upstream).

It is important to note that these indexes are only partly explicative of the peak flow deviation due to the spatial variability of rainfall. It can be easily understood that the two indexes which summarize this influence cannot replace a hydrological model. Figure 2 summarizes the proposed approach.

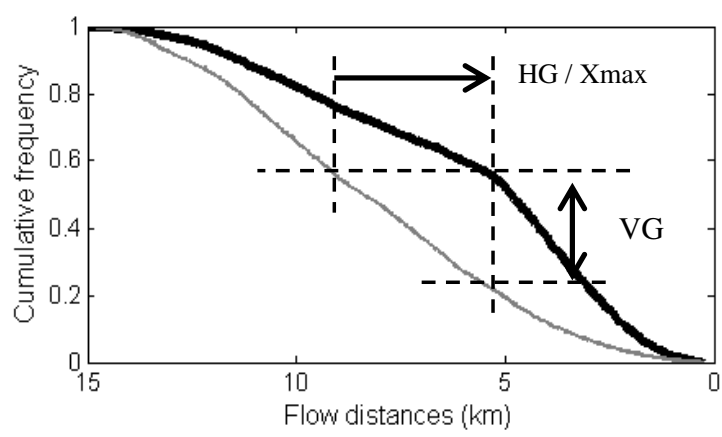

Figure 2. Principle of computation of the rainfall variability indexes VG and $\mathrm{HG}$ based on the catchment width function (fine line) and the rainfall width function (thick line). Xmax is the length of the longest hydrological path of the catchment.

A key point is the determination of the rainfall accumulation period on which the variability indexes should be computed. [1] concluded that the best representativeness was obtained by computing the indexes on the raw rainfall accumulation observed just before the hydrograph peak, i.e. between $\left[T_{Q^{-}} X \operatorname{Tr} ; T_{Q}\right]$, $\operatorname{Tr}$ being the catchment response time and $T_{Q}$ the time of the hydrograph peak, and $X$ being included in a [1.5 - 3] range. A $X$ value of 3 was selected here, and it was verified that the results were not significantly different for a $X$ value of 1.5 . The relatively low sensitivity to the $X$ value shows that $T r$ has not to be determined very accurately. It was therefore just evaluated for the 16 
catchments studied herein based on a pre-existing regional regression based on catchment surfaces.

\subsection{Definition of the splitting criterion}

Each of the studied hydrograph $\mathrm{Hi}$ is associated with a couple of indexes $\left(\mathrm{VG}_{\mathrm{i}}, \mathrm{HG}_{\mathrm{i}}\right)$ which characterizes the influence of rainfall spatial variability on catchment response. The set of hydrographs can be represented on a graph with VG and HG as axis, as displayed in Figure 3.

The splitting of the set of hydrographs is based on a unique criterion $\mathrm{C}(\mathrm{Hi})$ combining both $\mathrm{VG}_{\mathrm{i}}$ and $\mathrm{HG}_{\mathrm{i}}$ index values, and corresponding to the equation of an ellipse on Figure 3:

$$
C\left(\mathrm{H}_{\mathrm{i}}\right)=V G_{i}{ }^{2} / V G_{a v}{ }^{2}+H G_{i}{ }^{2} / H G_{a v}{ }^{2}
$$

$V G_{a v}$ and $H G_{a v}$ are the mean values of rainfall variability indexes for all tested hydrographs.

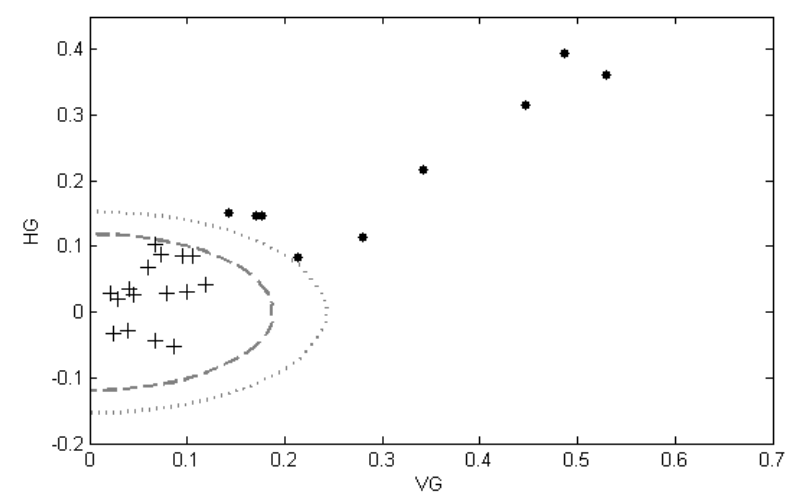

Figure 3. Values of VG and HG for each of the 25 tested hydrographs for subset A (dots) and subset B (plus). Equation 3 for $C$ equals to 1.5 (dashed line) and 2.5 (dotted line) are represented.

According to a threshold value $C$ to be defined and its $C\left(H_{i}\right)$ value, each hydrograph $H_{i}$ will be affected to a subset of hydrographs:

- Subset A including hydrographs with "significant influence of rainfall variability expected" (domain located outside the ellipse $C(H i)=C$ )

- Subset B including hydrographs with "weak influence expected" (domain located inside the ellipse).

For the present case study, values of $C$ ranging between 1.5 and 2.5 allow to define without any ambiguity the two subsets A and B. Nevertheless, it is clear that the choice of this threshold could be less obvious in future applications of the method.

\subsection{Evaluation of the modelling results for the two subsets}

The effects of information on spatial variability of rainfall (high resolution QPEs) on the modelling results will be assessed by comparing two scenarios for each subset [1]: 1) "distributed rainfall", whereby the hydrological model is forced by QPEs at the spatial resolution of radar data (i.e. $1 \mathrm{~km} \times 1 \mathrm{~km}$ ), so as to obtain a so-called "distributed hydrograph"; and 2) "average rainfall", whereby the hydrological model is forced by a spatially averaged rainfall field equal to the average rainfall intensity over the tested catchment. In this instance, the model gives a so-called "spatially averaged hydrograph" or "average hydrograph" hereafter.

Each of the modelled hydrographs (distributed and average) is compared to the observed hydrograph. This comparison is intended to verify whether considering the information on rainfall spatial variability allows for a better reproduction of the catchment response to rainfall forcing.

The hydrograph comparison performed herein is focused on peak flows [16], in accordance with two criteria: the level difference (denoted $\mathrm{L}_{\mathrm{Q}}$ ), and the time difference $\left(\right.$ denoted $\mathrm{T}_{\mathrm{Q}}$ ) between the peaks, i.e.:

$$
\begin{array}{r}
L_{Q}=100\left(Q_{\max }-Q_{M}\right) / Q_{\max } \\
T_{Q}=100\left(T_{Q \max }-T_{\max M}\right) / T_{Q \max }
\end{array}
$$

with $Q_{\max }$ being the maximum value of the observed hydrograph, and $Q_{M}$ the associated value of the modelled hydrograph (distributed or average) at the same time. $T_{\text {Omax }}$ is the time of occurrence of $Q_{\max }$, and $T_{Q \max M}$ the time of occurrence of the maximum value of the modelled hydrograph (distributed or average).

\section{Results}

Among the 25 selected hydrographs, 9 are classified in the subset A (significant influence of rainfall spatial variability expected) whereas 16 hydrographs are classified in the subset B (weak influence expected). Examples of rainfall accumulations on the tested catchments are shown on Figure 4. The examples displayed in Figure 5 illustrate the variety of situations that can be met. For hydrographs B1 and B2, the hydrological model does not work correctly, and the modelling errors appear very large if compared to the weak influence of rainfall variability. For instance, for $\mathrm{B} 2$, rainfall accumulation is relatively uniform over the catchment, and the value of $C\left(B_{2}\right)$ is close to 0 . Logically, for this event distributed and average hydrographs are very similar. Conversely, for $\mathrm{A} 1$ and $\mathrm{A} 2$, the average rainfall results in an underestimation of the observed hydrograph, whereas the distributed rainfall enables to obtain a model peak value close to the observed one. 

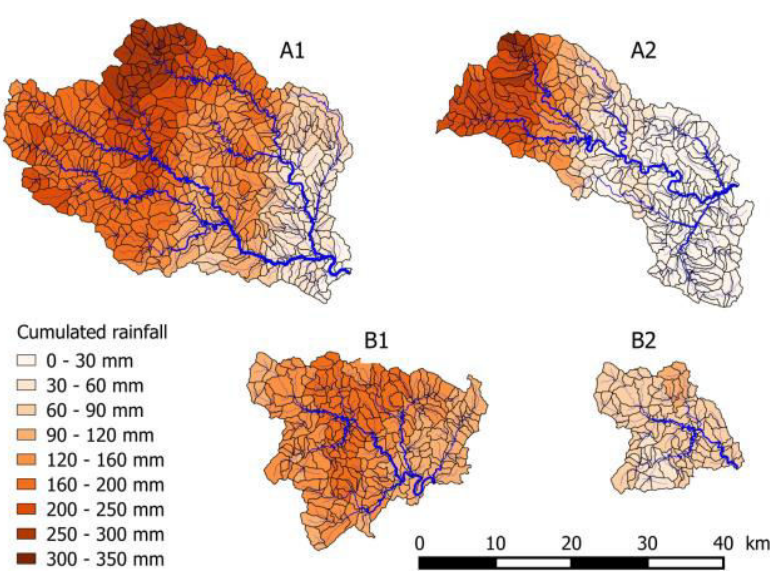

Figure 4. Representation of rainfall accumulation (in $\mathrm{mm}$ ) computed over a $3 \mathrm{Tr}$ duration before the hydrograph peak with $\mathrm{Tr}$ the response time of the catchment. A1 and A2 occurred the $31 / 10 / 2008$, on respectively a $1096 \mathrm{~km}^{2}$ and a $665 \mathrm{~km}^{2}$ catchment with $C(A 1)=1.36$ and $C(A 2)=10.0$. B1 and $\mathrm{B} 2$ occurred the $29 / 10 / 2010$, on respectively a $501 \mathrm{~km}^{2}$ and a 212 $\mathrm{km}^{2}$ catchment with $C(B 1)=0.23$ and $C(B 2)=0.06$.
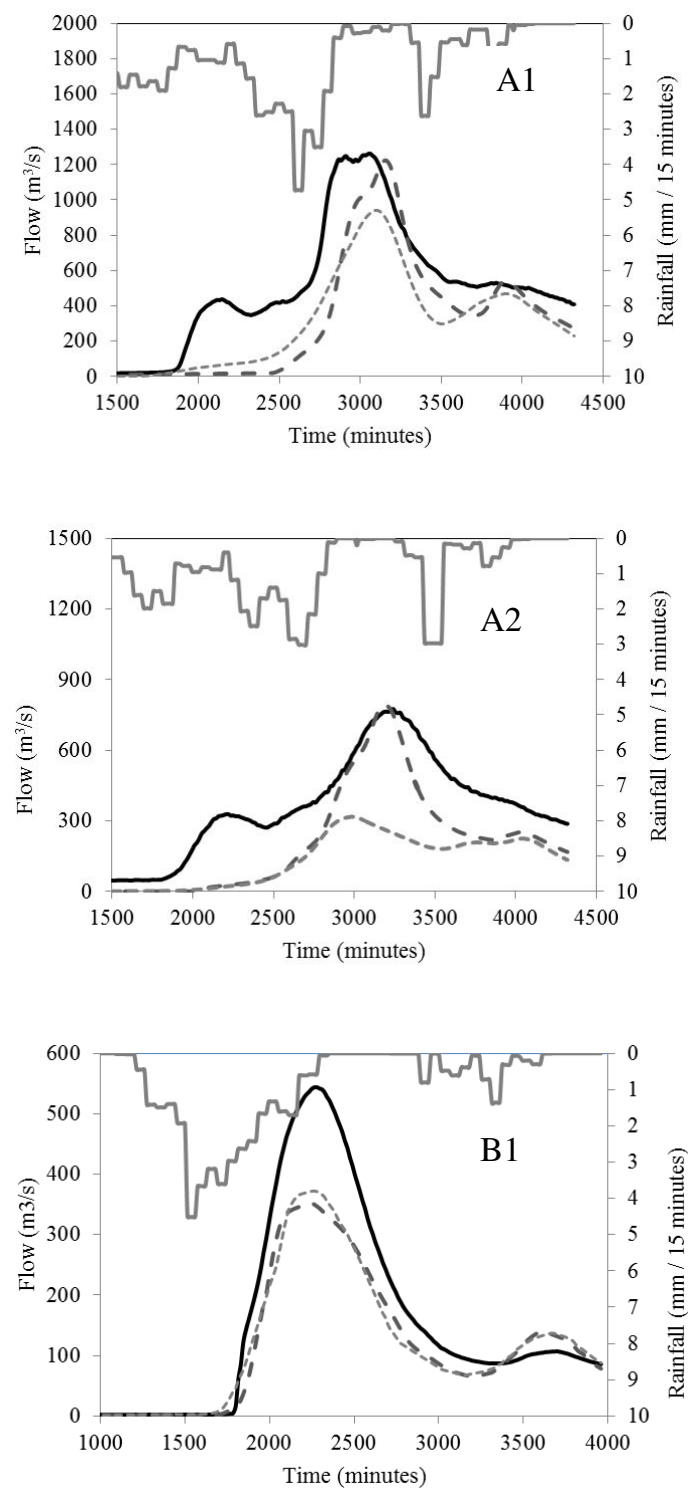

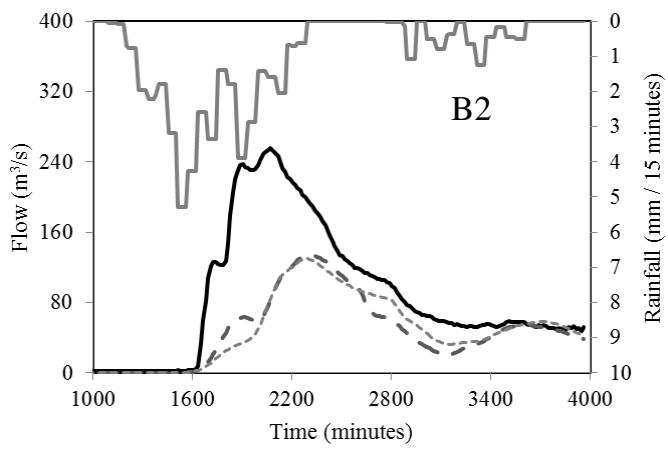

Figure 5. Examples of comparison between observed (solid line), distributed (dashed line) and average (dotted line) hydrographs. A1 and A2 are hydrographs classified in the sample "sensitive to the spatial variability of rainfall". B1 and B2 are hydrographs classified in the sample "weakly sensitive to the spatial variability of rainfall".

The distributions of level and time differences $\left(\mathrm{L}_{\mathrm{Q}}, \mathrm{T}_{\mathrm{Q}}\right)$ computed for average and distributed hydrographs are compared on Figure 6 for both subsets A and B.

For subset $\mathrm{B}$, the distributions of computed $\mathrm{L}_{\mathrm{Q}}$ are very similar for distributed and average hydrographs. For instance, median values are respectively equal to $48.3 \%$ against $49.5 \%$, and the third quartile equal to $68.5 \%$ against $67 \%$. The distributions of $\mathrm{T}_{\mathrm{Q}}$ values are also similar with median values equal to $19.9 \%$ against $25.3 \%$.

On the contrary, for subset A, the distributions of computed $\mathrm{L}_{\mathrm{Q}}$ seem significantly different between average and distributed hydrographs. The box plots are much more differentiated with median values respectively equal to $52 \%$ against $67.5 \%$, and the third quartile equal to $56.5 \%$ against $77.1 \%$. Those differences are also observed for $\mathrm{T}_{\mathrm{Q}}$ values with median values equal to $29.2 \%$ against $48.2 \%$.

This result reflects that subset A (regrouping events for which rainfall spatial variability is expected, according to the rainfall indexes, to exert a significant influence) is very different from subset B (regrouping events for which rainfall spatial variability is expected to exert a weak influence). For subset A, using distributed rainfall inputs enables to reduce the differences between modelled and observed hydrographs. This confirms that the information on spatial variability of rainfall deserves to be taken into account for these rain events. Whereas, for subset B, using distributed rainfall inputs does not enable to better model the hydrographs at the catchment outlet than using average rainfall over the catchment.

It is also important to notice on figure 6 what would happen without splitting subsets $\mathrm{A}$ and $\mathrm{B}$ : in this last case, the distributions of $\mathrm{L}_{\mathrm{Q}}$ and $\mathrm{T}_{\mathrm{Q}}$, even if not exactly identical between average and distributed hydrographs, cannot be distinguished as clearly as for the subset A considered separately. Logically in this case, merging flood events associated with both low or huge spatial rainfall variability makes much more difficult the 
identification of the benefits associated with high resolution information on rainfall.
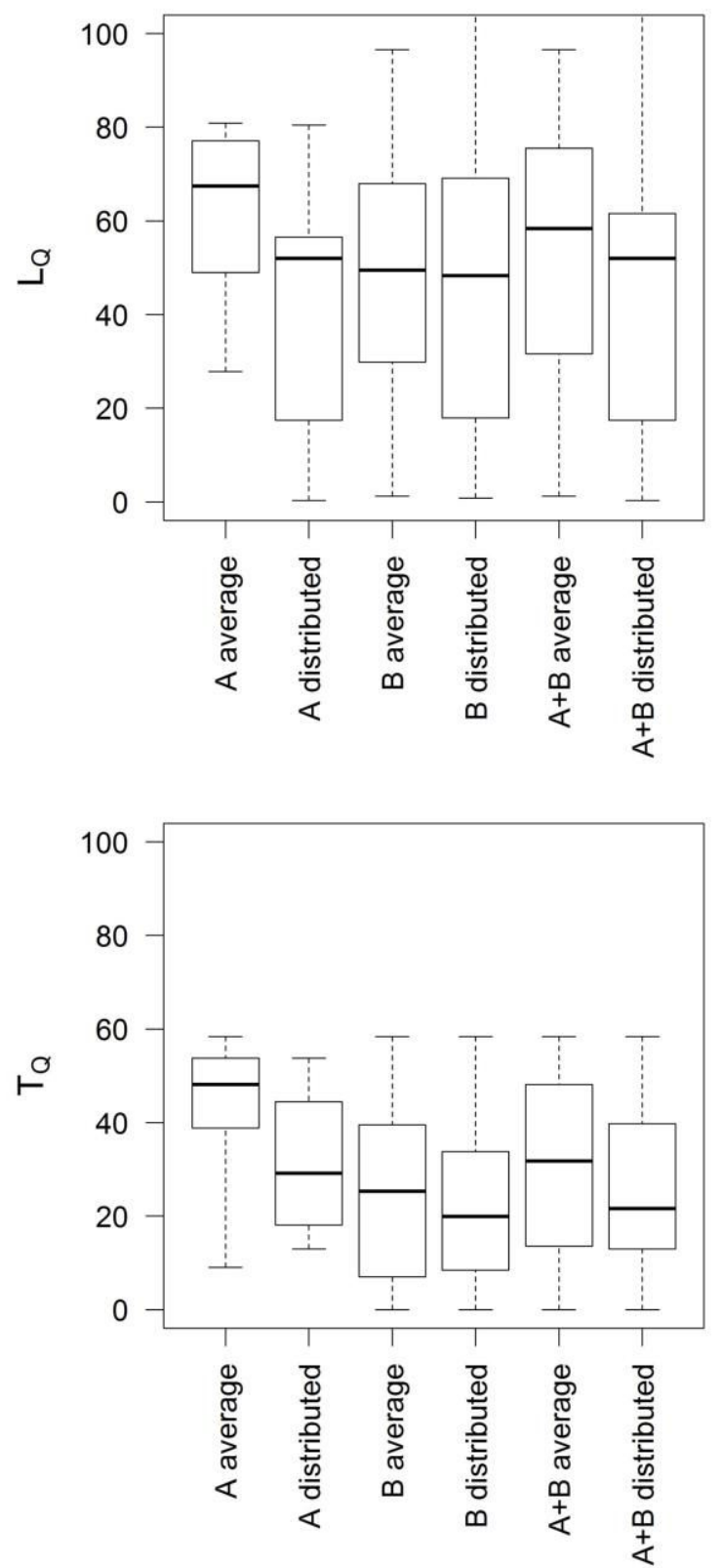

Figure 6. Comparison of the distributed and average modelled hydrographs with the observed hydrographs, based on the $\mathrm{L}_{\mathrm{Q}}$ (a) and $\mathrm{T}_{\mathrm{Q}}$ (b) criteria, for both subsets $\mathrm{A}$ and $\mathrm{B}$ and the whole dataset $\mathrm{A}+\mathrm{B}$. Box plots represent the first quartile, the median, the third quartile and the minimum and maximum values.

Finally, according to the events analysed in this case study, the rainfall variability indexes proposed by [1] appear to be helpful to detect situations for which rainfall spatial variability exerts a significant influence on the shape of hydrograph at the catchment outlet, and for which information on this variability (high resolution QPEs) should provide significant improvements in hydrograph modelling results.

\section{Discussion}

\subsection{About the possibility to split the dataset in two separate groups}

The dataset presented herein enables a clear distinction between the two subsets A and B based on the proposed criterion combining the rainfall variability indexes of [1]. Depending on the climatology of the considered region, it is likely that the distinction between subsets A and B will be much more difficult in other case studies: the computed $\mathrm{C}(\mathrm{Hi})$ values possibly being relatively close for all the tested events. If encountered, this difficulty will nevertheless traduce a relative homogeneity of the events in terms of rainfall spatial variability (low or significant variability for all the events). In such a situation, and in case of a large variability of rainfall, the distributions of $\mathrm{L}_{\mathrm{Q}}$ and $\mathrm{T}_{\mathrm{Q}}$ computed on the whole dataset (without splitting) should be significantly different for averaged and distributed hydrographs. Therefore, the potential added value of incorporating high resolution rainfall information in hydrological models should be much easier to identify without splitting the dataset in this case.

\subsection{About the size of the catchments being influenced by rainfall variability}

Unfortunately, the limited number of hydrographs combined in each subset does not allow for an in-depth analyse of the results. Nevertheless, it should be pointed out that the mean surface area of the catchments is much larger for hydrographs of subset A (significant influence of rainfall variability, $743 \mathrm{~km}^{2}$ ) than for events of subset $\mathrm{B}$ (weak influence, $354 \mathrm{~km}^{2}$ ). Let's keep in mind that all the rain events considered here are associated with similar meteorological conditions causing heavy rainfall in South of France [7]. This result might indicate that, for this category of rain events, the minimum area of catchments for which the spatial variability of rainfall may be large enough to have a significant effect on the shape of the hydrograph at the catchment outlet, could be in the interval $\left[350 \mathrm{~km}^{2}, 740 \mathrm{~km}^{2}\right]$. This result may be directly related to the climatology of the considered region, which may limit the probability to observe large rainfall gradients in basins of limited size. The analysis of a much larger set of hydrographs is nevertheless required to confirm this preliminary result and to provide a narrow interval.

\subsection{About the influence of temporal variability}

The influence of temporal rainfall variability may be another reason for incorporating information from high resolution QPEs in hydrological modelling. Radar based QPEs, indeed, offer the opportunity to reach a $5 \mathrm{~min}$ temporal resolution which may be useful if compared to the conventional 1 hour resolution generally offered by rainfall fields based on kriging of raingauge data. It is usually accepted that a time step ranging between $1 / 2$ and $1 / 5$ of the catchment response time is suited to correctly 
represent the rising part of the hydrograph, before the peak flow, which may require to adopt a less than $1-\mathrm{h}$ time step in small catchments.

Unfortunately, the 1-h time step of rainfall inputs used for this study do not enable to address this question, which was not the scope of this work. Provided that the temporal resolution of rainfall inputs used herein is always the same, the results presented illustrate the impacts of spatial information on rainfall, for a fixed temporal resolution. Therefore, the possible effects of interactions between temporal and spatial variability cannot be observed herein. However, the effects of rainfall concentration in space and time being both to increase the peak discharge values, it seems likely to us that the positive effect of using high spatial resolution information on rainfall may be increased if a higher temporal resolution is adopted.

\subsection{About the choice of a highly distributed model of the analysis}

The distributed model used for the analysis has been selected for its high spatial resolution, being close to the $1 \mathrm{~km} \times 1 \mathrm{~km}$ resolution of QPEs used as input. We didn't use herein a lumped model which may take benefit of its simplicity and of enhanced possibilities of calibration if compared to our distributed model. The question of the most suited modelling approach, indeed, was not the core of this study, which was limited to the identification of rainfall events for which spatial information on rainfall is a key point enabling to enhance modelling results.

However, it should be noticed that the methodology proposed would probably be helpful to compare several modelling approaches, including both lumped and distributed models. Based on the same procedure of separation of hydrographs in two subsets, the comparison of respective performances of models in both situations may illustrate both the advantages offered by a calibrated lumped model in situations of low rainfall variability, and how these advantages may be counterbalanced using a distributed model in case of high variability of rainfall.

\section{Conclusion}

The objective of this study was to illustrate the usefulness of rainfall variability indexes developed by [1] in a real world case study, to identify the influence of rainfall spatial variability on hydrograph modelling results at catchment outlet.

The case study presented is based on the analysis of 25 hydrographs recorded on 16 catchments of various surface areas, in the Cevennes region (south-eastern France) from 2008 to 2012. According to the rainfall spatial variability index values, the tested flood events were classified into two subsets combining respectively: i) the hydrographs expected to be significantly affected by rainfall variability (subset $\mathrm{A}$ ); and ii) the hydrographs expected to be weakly affected by this variability (subset B). The modelling results are then examined and compared with two rainfall inputs configurations: a spatially distributed knowledge with a detailed spatial resolution ( $1 \mathrm{~km} \quad \mathrm{x} \quad 1 \mathrm{~km})$, and a spatially-averaged knowledge at the catchment scale. The comparison of hydrographs has been focused on the deviations between hydrographs peaks times and values. Results show that, on average, the influence of taking rainfall spatial variability into account very significantly differs for the two subsets: the added value is clear in the case of subset A, whereas it is not identified in case of subset B.

Therefore, this case study confirms the interest of the proposed method to identify the effects of rainfall spatial variability on hydrograph modelling results at catchment outlet. The two rainfall spatial variability indexes used appear able to detect situations for which rainfall spatial variability exerts a significant influence on catchment response. Their main advantage is that their computation is only based on the characteristics of the raw rainfall field, enabling to separate the rainfall events independently of the model tested. This separation appears here to be of great help to better analyse and understand the modelling results.

Nevertheless, due to the limited number of tested hydrographs, this study does not contribute explaining in detail the conditions (catchment features, rainfall structure) leading to a significant effect of rainfall spatial variability. For better understanding of these conditions, it is required to extend this study to a much larger and more varied set of catchments and rain events in order to acquire a more general point of view of the rainfall spatial variability influence. Such a step could involve, for example, pursuing the contribution of [6] which is based on a much larger number of catchments.

\section{Acknowledgements}

The work presented in this paper has been supported by SCHAPI (Service Central d'Hydrométéorologie et d'Appui à la Prévision des Inondations). The series of rainfall fields, derived from radar images, have been provided by the OHMCV (Guy Delrieu and Brice Boudevillain, LTHE).

\section{References}

1. Emmanuel I., Andrieu H., Leblois E., Janey N. and Payrastre, O. (2015). The use of indexes to evaluate the influence of rainfall spatial variability on rainfallrunoff modelling: worth of a simulation approach? $J$. Hydrol., doi:10.1016/j.jhydrol.2015.04.058

2. Looper J.P. and Vieux B.E. (2012). An assessment of distributed flash flood forecasting accuracy using radar and rain gauge input for a physics-based distributed hydrologic model. J. Hydrol., 412, 114132.

3. Adams R., Western A.W. and Seed A.W. (2012). An analysis of the impact of the spatial variability in rainfall on runoff and sediment predictions from a distributed model. Hydrol. Process., 26, 3263-3280.

4. Tarolli M., Borga M., Zoccatelli D., Bernhofer C., Jatho N. and Janabi F. (2013). Rainfall space-time 
organization and orographic control on flash flood response: the Weisseritz event of August 13, 2002. J. Hydrol. Eng., 18(2), 183-193.

5. Pokhrel P. and Gupta H.V. (2011). On the ability to infer spatial catchment variability using streamflow hydrographs. Water Resour. Res., 47, W08534, doi:10.1029/2010WR009873

6. Lobligeois F., Andréassian V., Perrin C., Tabary P. and Loumagne, C. (2014). When does higher spatial resolution rainfall information improve streamflow simulation? An evaluation using 3620 flood events. Hydrol. Earth Syst. Sci., 18, 575-594.

7. Boudevillain B., Delrieu G., Bonnifait L., Bouilloud L., Kirstetter P.E. and Mosini M.L. (2011). The Cévennes-Vivarais Mediterranean hydrometeorological observatory database. Water Resour Res., 47:W07701. http://dx.doi.org/10.1029/ 2010WR010353

8. Delrieu G., Wijbrans A., Boudevillain B., Faure D., Bonnifait L. and Kirstetter P.E. (2014). Geostatistical radar-raingauge merging: A novel method for the quantification of rain estimation accuracy. Adv. Water Resour., 71, 110-124.

9. Naulin J.P., Payrastre O. and Gaume E. (2013). Spatially distributed flood forecasting in flash flood prone areas: Application to road network supervision in Southern France. J. Hydrol., 486, 88-99.

10. Moussa R. (1996). Analytical Hayami solution for the diffusive wave flood routing problem with lateral inflow. Hydrol. Process., 10, 1209-1227.

11. Perrin C., Michel C. and Andréassian V. (2003). Improvement of a parsimonious model for streamflow simulation. J. Hydrol., 279, 275-289.

12. Smith M.B., Koren V.I., Zhang Z., Reed S.M., Pan J.J. and Moreda F. (2004). Runoff response to spatial variability in precipitation: an analysis of observed data. J. Hydrol., 298(1), 267-286.

13. Zoccatelli D., Borga M., Zanon F., Antonescu B. and Stancalie G. (2010). Which rainfall spatial information for flash flood response modelling? A numerical investigation based on data from the Carphatian range, Romania. J. Hydrol., 394(1-2), 148-161.

14. Zoccatelli D., Borga M., Viglione A., Chirico G.B. and Blöschl G. (2011). Spatial moments of catchment rainfall: rainfall spatial organization, basin morphology and flood response. Hydrol. Earth Syst. Sci., 15, 3767-3783.

15. Rodríguez-Iturbe and Rinaldo, 1997. Fractal River basins. Chance and Self-Organisation. Press syndicate of the University of Cambridge, Cambridge, UK, 547 p.

16. Sangati M., Borga M., Rabuffetti D. and Bechini R. (2009). Influence of rainfall and soil properties spatial aggregation on extreme flash flood response modelling: an evaluation based on the Sesia river basin, North Western Italy. Adv. Water Resour., 32(7), 1090-1106. 